\title{
New approaches to achieve high level enzyme production in Streptomyces lividans
}

\author{
Laura Sevillano ${ }^{1}$, Erik Vijgenboom², Gilles P. van Wezel ${ }^{2}$, Margarita Díaz ${ }^{1 *}$ and Ramón I. Santamaría ${ }^{* *}$
}

\begin{abstract}
Background: Actinomycetes are saprophytic soil bacteria, and a rich source of industrial enzymes. While some of these enzymes can be produced using well-characterized production platforms such as Escherichia coli or Bacillus subtilis, Streptomyces lividans may be the preferred host for proper folding and efficient secretion of active enzymes. A combination of promoters, signal peptides and hosts were tested in order to obtain the best protein expression in this actinomycete. The xylanase, Xys 1, from S. halstedii, the a-amylase, Amy, from S. griseus and the small laccase, SLAC, from S. coelicolor were used as reporters.

Results: The promoters xysAp from S. halstedii JM8 and pstSp from S. lividans were the most efficient among those tested. An improvement of $17 \%$ was obtained in xylanase activity when the signal peptide of the a-amylase protein (Amy) of S. griseus IMRU3570 was used to direct its secretion. Enhanced expression of SsgA, a protein that plays a role in processes that require cell-wall remodelling, resulted in a improvement of 40 and $70 \%$ of xylanase and amylase production, respectively. Deletion of genes SL17232 and SL/4452 encoding putative repressors of xysAp provided improvement of production up to $70 \%$ in the SLI7232 deletion strain. However, full derepression of this promoter activity was not obtained under the conditions assayed.
\end{abstract}

Conclusions: Streptomyces lividans is a frequently used platform for industrial enzyme production and a rational strain-development approach delivered significant improvement of protein production by this host.

Keywords: Streptomyces, Protein production, Xylanase, Amylase, Laccase, Vector optimization

\section{Background}

The production of proteins of industrial interest at low cost is one of the main goals of biotechnology. Escherichia coli has usually been a preferred host for protein production, for reasons of high expression levels and short fermentation time. However, frequently insoluble inclusion bodies are formed, which frustrates downstream processing [1-3]. In such cases, alternative production platforms are required, and microorganisms of the genus Streptomyces have been successfully applied as a good alternative expression platform for heterologous protein production [4-10]. Streptomycetes are aerobic,

\footnotetext{
*Correspondence: mardi@usal.es; santa@usal.es

${ }^{1}$ Instituto de Biología Funcional y Genómica/Departamento de Microbiología y Genética, Consejo Superior de Investigaciones Científicas (CSIC)/Universidad de Salamanca, C/Zacarías González n², 37007 Salamanca, Spain

Full list of author information is available at the end of the article
}

filamentous Gram-positive soil bacteria that secrete a wide range of extracellular enzymes, which they require to be able to feast on natural polymers such as starch, cellulose, chitin, mannan or xylan. Their use as a production hosts could overcome some of the problems encountered with other systems: streptomycetes do not readily form inclusion bodies, they have a relatively low level of extracellular protease activity, are well suited to expressing GC-rich genes, and have a high secretion capacity. These properties are very useful for directing the expressed protein in a soluble configuration to the culture supernatant, a major advantage in terms of downstream processing.

Nevertheless, the mycelial lifestyle of actinomycetes results in heteromorphous and viscous cultures, which are unfavourable for industrial fermentation, due to mass-related mechanical stress, heat transfer problems and oxidative stress [11]. Enhanced fragmentation of the mycelia has a major impact on growth and product 
formation by these organisms and is therefore expected to have an impact on biotechnological applications requiring Streptomyces as the production host $[12,13]$. The morphology of liquid-grown mycelia is dictated by external factors (media and fermentation conditions), but also by genetic factors. An important example in this respect is the effect of SsgA, which controls all processes that require remodelling of the cell wall, such as germination, tip growth, branching and septum formation [14, 15]. Overexpression of SsgA not only leads to fragmentation of the mycelia, but also to enhanced secretion, with almost three-fold increase of tyrosinase production by Streptomyces lividans during batch fermentation [16].

In this work, we show that selection of strong promoters, modification of signal peptides and use of different $S$. lividans hosts result in improved production of putative industrial proteins such as the xylanase Xys1 from $S$. halstedii JM8, the $\alpha$-amylase Amy from S. griseus IMRU3570 and the small laccase SLAC from S. coelicolor.

In addition, two transcriptional repressors, $X \ln R$ and BlxR, have been identified in S. lividans that take part in the control of the xysA promoter activity. This provides new handles for the application and further development of the $x y s A$ promoter as a tool in enzyme production.

\section{Results}

Promoter choice has a drastic effect on protein expression

In order to find suitable promoters to express proteins in Streptomyces we tested six Streptomyces promoters for their ability to enable strong gene expression. These promoters are active during different phases of the developmental cycle or regulated by different carbon sources. Two of these were strong promoters used frequently in other studies to express proteins in Streptomyces: vsip from S. venezuelae [17] and ermE*"p from Saccharopolyspora erythraea [18], the activity of which was compared to that of promoters of four highly expressed genes that are studied extensively in our laboratory. These promoters are the $x y s A$ p promoter belonging to the $x y s A$ gene from $S$. halstedii JM8 that encodes the xylanase Xys1 (U41627) [19], the pstS promoter (pstSp) from S. lividans (AJ698727), which drives transcription of the high-affinity phosphate-binding protein (PstS) [20], and the promoter $x y l A p$ of $x y l A$ (SCO1169, encoding xylose isomerase) and $g l p Q p$ of $g l p Q$ (SCO1968, encoding a glycerophosphoryl diester phosphodiesterase) from $S$. coelicolor.

The different promoter sequences were inserted upstream of the xylanase gene $x y s A$, which was cloned in a multicopy derivative of the bifunctional Streptomyces plasmid pN702GEM3 [21] (see "Methods"). A diagram of the plasmid and of the different constructs is presented in Fig. 1a, b. The constructs pNX24 (xysAp) [22], pNUF5

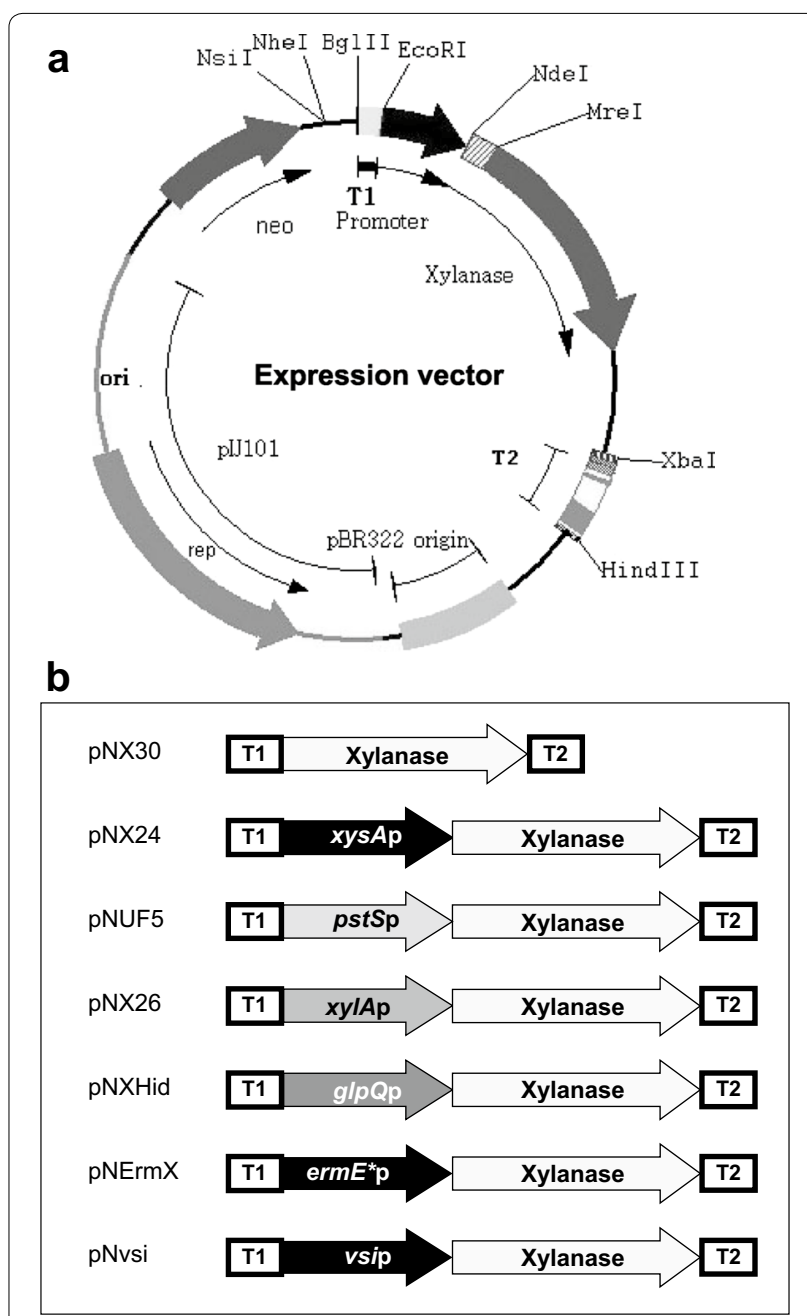

Fig. 1 Schematic representation of the plasmids obtained. a. General diagram of expression plasmids. The plasmid has the E. coli pBR322 origin and the replication region for Streptomyces from pIJ101. b. Different plasmids with the promoters tested. pNX30 is the control plasmid with a promoterless xylanase gene. pNX24, xysAp: promoter of xysA gene from S. halstedii (U41627); pNUF5, pstSp: promoter of the pstS gene from S. lividans (AJ698727); pNX26, xylAp: xylose isomerase promoter from S. coelicolor (SCO1169); pNXHid, glpQp: promoter of a putative hydrolase from S. coelicolor (SCO1968); pNErmX, ermE* $p$ : promoter of the erythromycin resistance ermE gene; $p N v s i$, vsip: promoter of the subtilisin inhibitor SSI from S. venezuelae (X98019); T1 and $\mathrm{T} 2$ are $\mathrm{mmrt}$ and $f d t$ transcriptional terminators

(pstSp) [20], pNX26 (xylAp), and pNXHid (glpQp), pNErmX (ermE* p), pNvsi (vsip) as well as the promoterless control plasmid pNX30 were introduced into S. lividans 1326 by protoplast transformation. Transformants were cultured at $28{ }^{\circ} \mathrm{C}$ in liquid YES medium with $1 \%$ xylose or YE with $5 \%$ fructose, as indicated in the Methods section and xylanase production was analyzed by SDS-PAGE of culture supernatants after 3, 5 and 7 days. Extracellular processing results in two bands for xylanase, Xys1L and Xys1S, with a mass of 43.5 and $33.7 \mathrm{kDa}$ 
respectively [19]. The Xys1S species has lost the C-terminal CBM2 domain but both xylanase species have similar specific activity with oat spelt xylan as substrate $[19,21]$.

The natural xylanase promoter, $x y s A \mathrm{p}$, and the $p s t S$ promoter, $p s t S \mathrm{p}$, resulted in the highest xylanase production (Fig. 2a lanes 2 and 3). The xylanase production

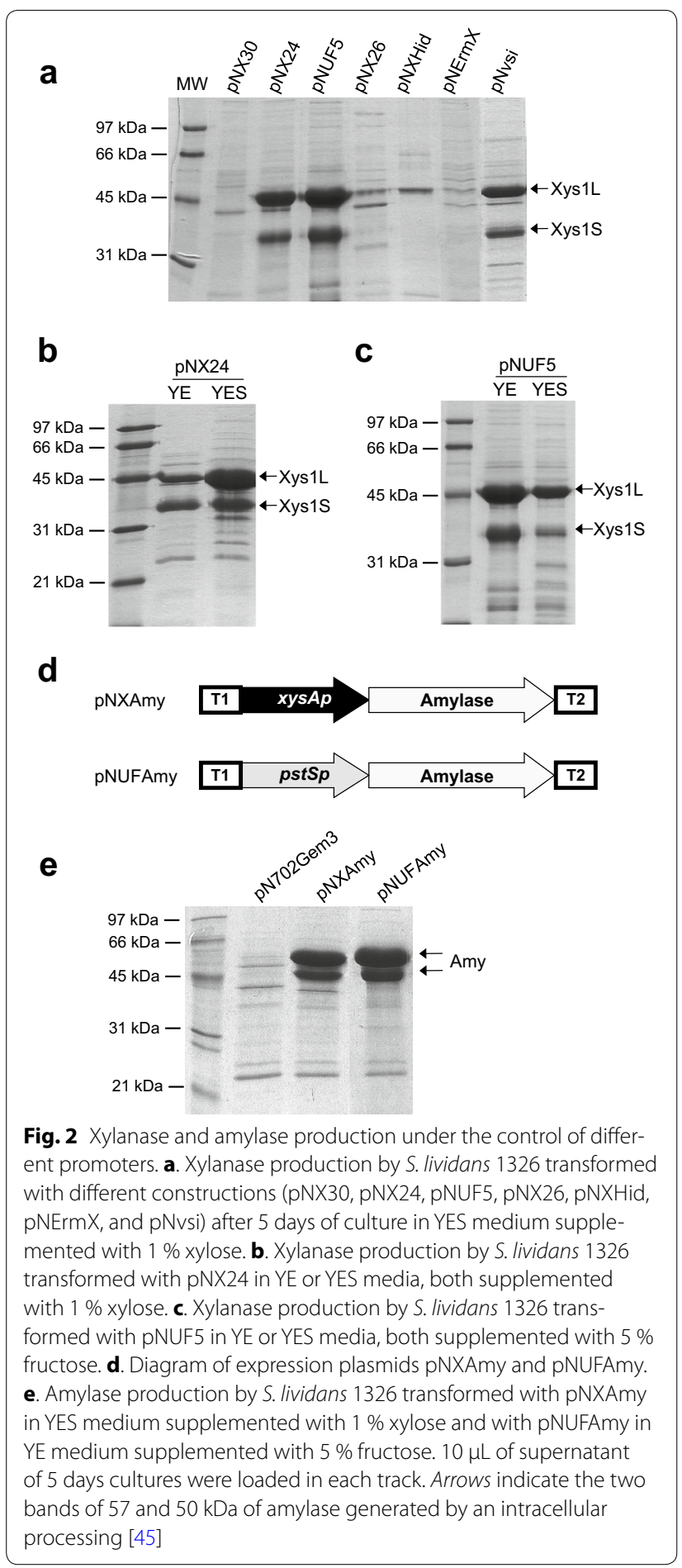

under the control of $e r m E^{*}$ p was poor (Fig. 2a lane 6) and, although production under the control of $v$ sip was high, this was lower than that obtained with $x y s A \mathrm{p}$ and pstSp (Fig. 2a lane 7 versus lanes 2 and 3). Maximum xylanase levels were reached after 5 days, the production did not increase by longer incubation (data not shown).

The production of xylanase under control of $x y s A \mathrm{p}$ and $p s t S \mathrm{p}$ was strongly dependent on the culture medium. For xysAp (pNX24) the highest protein production was obtained in YES medium supplemented with $1 \%$ xylose (Fig. 2b), while for pstSp (pNUF5) the highest production was obtained in YE medium in the presence of $5 \%$ of fructose [20] (Fig. 2c).

To demonstrate that $x y s A \mathrm{p}$ and $p s t S \mathrm{p}$ are generally applicable for enzyme production, they were used to drive the expression of $\alpha$-amylase (Amy) from S. griseus obtaining the plasmids pNXAmy and pNUFAmy respectively (Fig. $2 \mathrm{~d}$ ). High production levels of this enzyme were also obtained demonstrating the potential of these promoters to express other proteins of interest (Fig. 2e).

\section{Modification of the secretion signal peptide improves protein export}

Changes in the signal peptide might be advantageous for secretion efficiency and therefore for increasing the production of heterologous proteins [23, 24]. In order to compare the efficiency of the $\alpha$-amylase (Amy) signal peptide with that of xylanase (Xys1), we replaced the codons for the Xys1 signal peptide in pNX24 (first 45 codons) by those for the corresponding Amy signal peptide (28 codons) [25], resulting in pNXA1 (Table 1, Fig. 3a). A xylanase derivative with the complete Amy signal peptide coding sequence including the first three codons of the mature amylase was also constructed in order to maintain the environment of the amylase signal peptide-cleavage site (pNXA2, Fig. 3a).

Cultures of S. lividans harbouring either pNX24 or its derivatives pNXA1 or pNXA2 were grown at $28{ }^{\circ} \mathrm{C}$ for 5 days in liquid YES medium supplemented with $1 \%$ xylose; the amount of xylanase in the supernatant was analyzed by SDS-PAGE, xylanase bands intensities were determined with the ImageJ software and the activity quantified using the DNS assay ("Methods") (Fig. 3b, c and Additional file 1: Tables S1, S2). Replacing the original xylanase signal peptide with that of amylase resulted in a similar degree of xylanase secretion (pNXA1, Fig. 3c). However, an increase of $17 \%$ in xylanase activity was obtained when the amylase signal peptide with the three aminoacids extension was used (pNXA2) (Fig. 3c and Additional file 1:Table S2).

\section{Engineered hosts for improved protein yield}

The host used as platform for enzyme production is a major determinant for the yield that can be obtained. 
Table 1 Plasmids used in this work

\begin{tabular}{|c|c|c|}
\hline Plasmid & Characteristics & Reference \\
\hline pN702GEM3 & $\begin{array}{l}\text { E. coli-Streptomyces shuttle vector; contains the plJ702 origin of replication (for Streptomyces), the pUC origin of replication } \\
\text { (for E. coli) and a polylinker derived from pGEM3Zf(+) (Promega). It carries the bifunctional Neo/Kan resistance marker } \\
\text { from Tn5 (for both E. coli and Streptomyces) }\end{array}$ & [21] \\
\hline $\mathrm{pN} \times 30$ & $\begin{array}{l}\text { pN702GEM3 derivative. xys A xylanase ORF without any promoter and flanked by transcriptional terminators. Used as nega- } \\
\text { tive control }\end{array}$ & [35] \\
\hline $\mathrm{pN} \times 24$ & pN702GEM3 derivative. xysA promoter from S. halstedii controls xylanase expression & [22] \\
\hline pNUF5 & pN702GEM3 derivative. pstS promoter from S. lividans controls xylanase expression & [20] \\
\hline pNErmX & pN702GEM3 derivative. Erythromycin resistance promoter from S. erythraeus controls xylanase expression & This work \\
\hline pNvsi & pN702GEM3 derivative. vsi promoter from S. venezuelae controls xylanase expression & This work \\
\hline $\mathrm{pN} \times 26$ & pN702GEM3 derivative. Xylose isomerase promoter from S. coelicolor controls xylanase expression & This work \\
\hline pNXHid & pN702GEM3 derivate. Promoter of a putative hydrolase $(\mathrm{g} / \mathrm{pQ})$ from S. coelicolor controls xylanase expression & This work \\
\hline pNXA1 & pNX24 derivate. xysA promoter from S. halstedii controls xylanase expression with amylase signal peptide & This work \\
\hline pNXA2 & $\begin{array}{l}\text { pNX24 derivative. xysA promoter from S. halstedii. Controls xylanase expression with the amylase signal peptide with three } \\
\text { additional amino acids }\end{array}$ & This work \\
\hline pNXAmy & pN702GEM3 derivative. xysA promoter from S. halstedii controls amylase expression & This work \\
\hline pNUFAmy & pN702GEM3 derivative. pstS promoter from S. lividans controls amylase expression & This work \\
\hline pEPOS101 & pHJL401 derivative harbouring xysAp driving the expression of SLAC (SCO6712) & This work \\
\hline
\end{tabular}

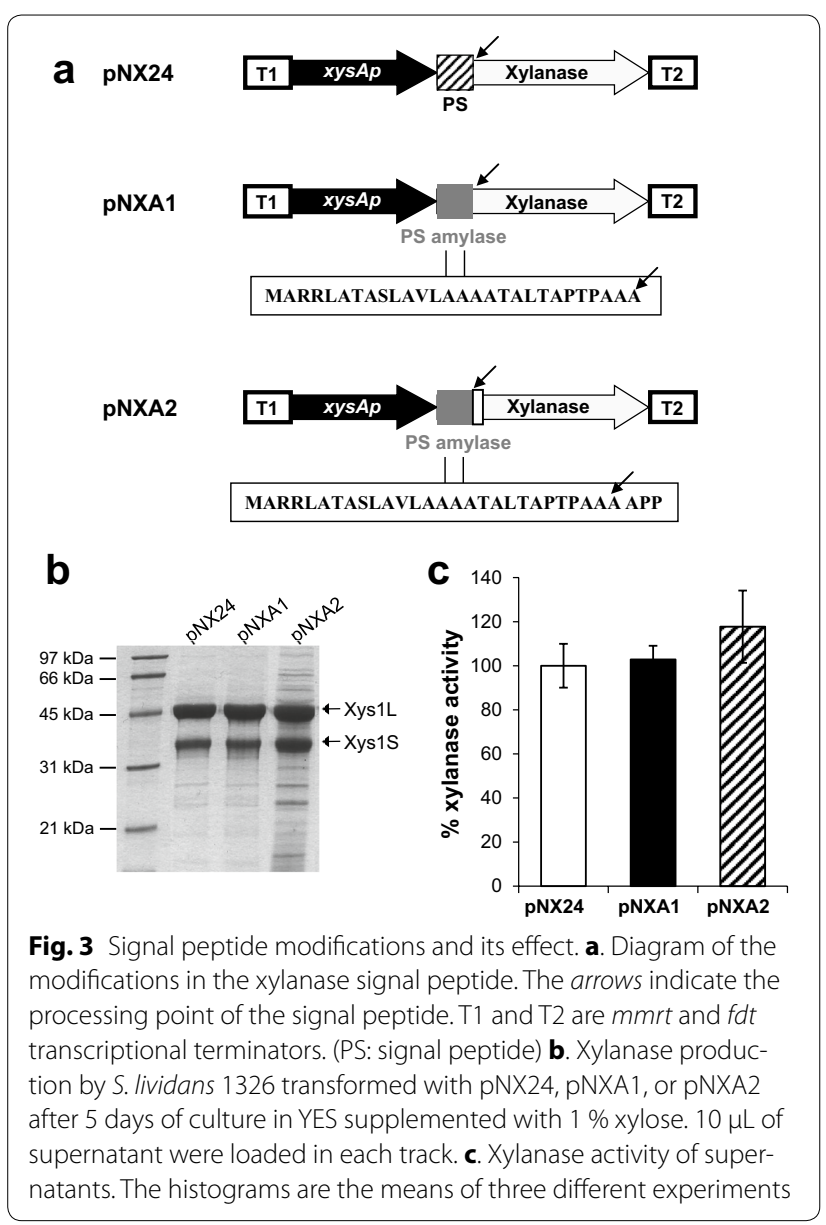

We explored two ways of improving the host: (1) the effect of host morphology on xylanase production and (2) the effect of putative repressors on xysA expression. To change the morphology we selected a S. lividans 1326 strain overexpressing SsgA (GSAL1) [16]. The $s s g A$ gene is a morphogene that pleiotropically affects growth and cell division [26]; it activates sporulation-specific cell division by ensuring the correct localization of SsgB, which in turn recruits FtsZ to future septum sites [27]. The enhanced expression of $s s g A$ leads to strongly enhanced septation in vegetative hyphae, which results in fragmented growth and much wider hyphae, a phenotype that favours protein production as well as secretion [16].

In order to establish the effect of SsgA overexpression on xylanase production, pNX24 was introduced to S. lividans 1326 and its derivative overexpressing SsgA (GSAL1). The transformants were grown for 5 days in YES medium with $1 \%$ xylose and the amount of xylanase in the culture supernatants was analysed by SDSPAGE (Fig. 4a) and the xylanase activity was quantified by the DNS protocol (Fig. 4b). Both, the total amount of xylanase (Xys1L + Xys1S) bands, as determined with ImageJ, and the enzyme activity increased in the SsgAoverexpressing host GSAL1. The band intensities in the SDS-PAGE increased by $70 \%$ while the enzyme activity increased by $40 \%$ (Fig. 4a, b and Additional file 1:Tables S3, S4).

Streptomyces lividans 1326 and GSAL1 were also transformed with pNXAmy harbouring the $\alpha$-amylase gene 

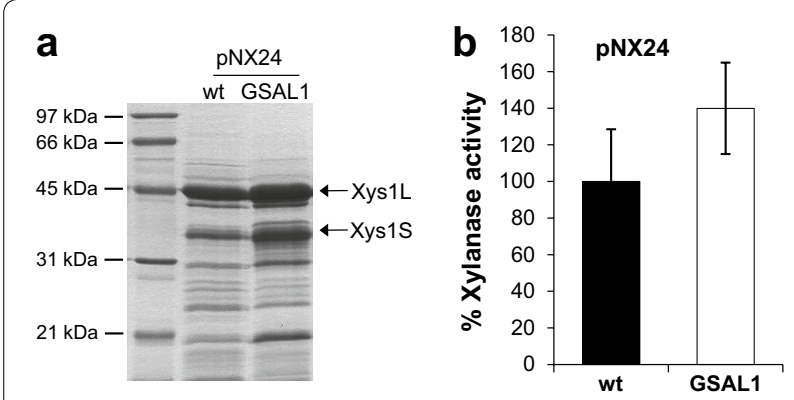

C

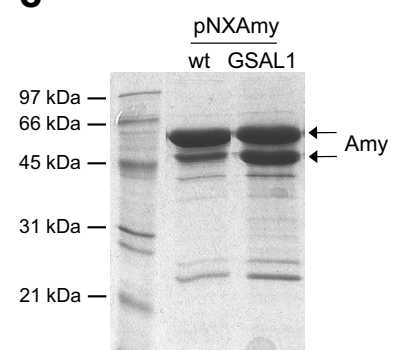

Fig. 4 SsgA effect on xylanase and amylase production. a. Xylanase production by S. lividans 1326 (wt) and the SsgA overproducer strain (GSAL1), transformed with pNX24 after 5 days of culture in YES supplemented with $1 \%$ xylose. b. Percentage of xylanase activity of supernatants. C. Amylase production by S. lividans 1326 (wt) and the SsgA overproducer strain (GSAL1) transformed with pNAmy after 5 days of culture in YES supplemented with $1 \%$ xylose. d. Percentage of amylase activity of supernatants. The histograms are the mean of three different experiments

under control of $x y s A p$, and the culture supernatants were analysed by SDS-PAGE (Fig. 4c) and the amylase activity of the samples was quantified by the DNS protocol (Fig. 4d). The GSAL1 transformant showed an increase of $45 \%$ in the band intensities while the amylase activity increased by $70 \%$ (Fig. 4c, d and Additional file 1:Tables S5 and S6). Both strains were also transformed with the empty plasmid (pN702GEM3) as a control showing no detectable xylanase or amylase activity in the quantification assays (data not shown).

The second approach was prompted by the observation that maximum enzyme production, controlled by xysAp, was obtained after 4 days of growth in liquid media with low accumulation after $24 \mathrm{~h}$ (data not shown). This suggests that a repressor(s) bound to $x y s A \mathrm{p}$ might be controlling its expression during the first days of growth. Carbon catabolite repression of $x y s A p$ was demonstrated previously and the role of different regions of the promoter studied [28]. Among them, a motif 5'-CGAAACTTTCG-3', also present in promoter regions of a number of $S$. lividans genes, all of them related to xylan metabolism (data not shown), seems to be important in the glucose control of this promoter [28]. This palindromic sequence is the binding site for BxlR,

a xylobiose responsive repressor in $S$. thermoviolaceus [29]. The homologue of BxlR in S. lividans is encoded by SLI7232. In addition to BxlR, another putative repressor, $\mathrm{X} \operatorname{lnR}$ (SLI4215) has been implicated in xylanase expression in S. lividans TK24 [30].

In order to test whether these two repressors may affect the temporal accumulation pattern of an enzyme which gene is controlled by $x y s A p$, the gene for the small laccase, SLAC [31] was used as reporter under the control of the $x y s A p$ (plasmid pEPOS101). SLAC was used as reporter to eliminate potential interference of the induction of host xylanases and xylose metabolism related enzymes in $b x l R$ and $x \ln R$ deletion strains.

Both repressor mutant strains (obtained as indicated in "Methods") showed an increased SLAC expression compared to the wild type parent, S. lividans 1326 . The highest increase was observed in the $\Delta b x l R$ strain with $70 \%$ more SLAC after $72 \mathrm{~h}$ of growth and $30 \%$ after $96 \mathrm{~h}$. However, the profile of enzyme activity over time was similar in all three strains and complete derepression was not obtained during the first 2 days of incubation suggesting additional levels of control (Fig. 5).

\section{Discussion}

The high-level production of heterologous proteins is a key objective in biotechnology. S. lividans is a preferred heterologous host for industrial production of proteins from prokaryotic and eukaryotic organisms [5, 10, 32]. It has several major advantages over the more traditional platforms such as E. coli and B. subtilis as well as compared to other Streptomyces species. These advantages include: (i) low endogenous extracellular proteolytic activity in comparison with other Streptomyces species

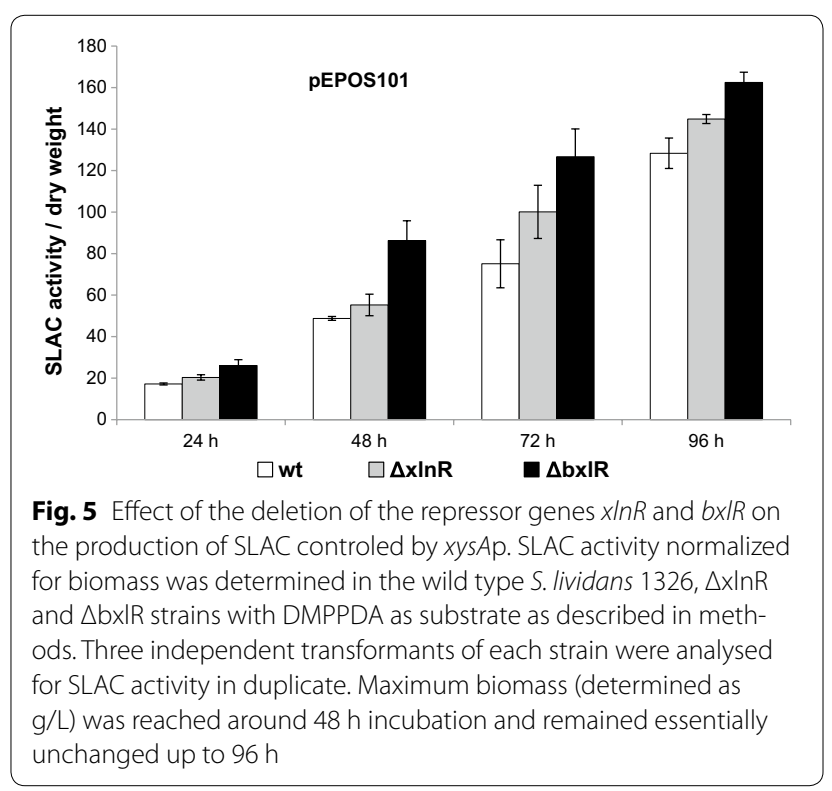


or Bacillus [33, 34]; (ii) the fact that S. lividans does not form inclusion bodies, as is often the case in E. coli; and (iii) its ability to produce bioactive proteins [5]. Furthermore, the Streptomyces protein secretion machinery very efficiently exports proteins of interest into the culture supernatant, which facilitates subsequent protein purification. However, S. lividans also has some significant drawbacks, which relate to the mycelial growth associated with slow growth and viscous cultures and the lack of well-established expression systems. Thus, the implementation of Streptomyces as a production platform requires the optimization of promoter/vector/host systems.

In this work, we expand the toolbox of available promoters in combination with secretion signals to improve protein production in S. lividans. Several strong, constitutive promoters have been previously described for Streptomyces, but the number of suitable inducible promoters is scarce [3]. We compared six promoters and obtained good expression of the reporter proteins Xys1 from S. halstedii and Amy from S. griseus using the promoters $x y s A \mathrm{p}$, which is induced by different carbon sources such as xylose, xylan and fructose and repressed by glucose [28], and $p s t S p$, induced by low phosphate conditions and by different carbon sources such as fructose, xylose or galactose [20,35,36]. These promoters resulted in more efficient and reproducible protein production than the widely applied Streptomyces promoters $e r m E^{*}$ p and vsip (Fig. 2a lanes 2 and 3 versus lanes 6 and 7). Therefore, the high-copy number E. coli and Streptomyces shuttle plasmids developed in this work; equipped with strongly inducible promoters (xysAp or pstSp), represent a good option for producing high levels of proteins of interest in Streptomyces as has been demonstrated for the xylanase, (Xys1) from S. halstedii, the $\alpha$-amylase (Amy) from S. griseus and laccase (SLAC) from S. coelicolor.

The elimination of the putative $x y s A \mathrm{p}$ repressors $\mathrm{X} \ln \mathrm{R}$ or BxlR from the host strains increased the protein production of the reporter SLAC in these mutants (up to $70 \%$ after $72 \mathrm{~h}$ in the $\Delta b x l R$ strain) indicating the suitability of these strains. Moreover, in the $\Delta b x l R$ strain, the activity is clearly induced earlier with an almost twofold higher SLAC production at the onset of stationary growth at $48 \mathrm{~h}$. The fact that repression is not completely relieved in these single mutants during logarithmic growth $(24 \mathrm{~h})$ suggests that multiple (negative) control mechanisms act on xysAp in S. lividans.

We then proceeded to test the effect of altering the signal peptide, the adaptation of which could be a valuable additional tool in the production process to obtain more efficient secretion. As reviewed by Lammertyn and
Anné [23], several modifications have been found that improve Streptomyces signal peptides, and some of these were applied successfully in the vectors developed in this study. We observed an improvement of $17 \%$ in xylanase secretion by changing the xylanase signal peptide for an amylase signal peptide with three additional amino acids from the mature amylase to maintain the sequence around the signal peptidase cleavage site (Fig. 3c). However, modification of the net charge of the amylase signal peptide as it has been described in amylase secretion [25] did not further improve xylanase production (data not shown). Thus, changes in the secretion signal that work for one protein do not necessarily also work for others because this effect is highly sequence dependent and may be also affected by the level of expression reached. Additionally, changing the $\mathrm{N}$-terminal part of the gene may also have repercussions at the level of translation.

As discussed above, protein production is not only about providing the optimal expression system, but also depends on the morphology of the production host, which is a major factor in determining production level as well as fermentation time. Problems associated with the fermentation of filamentous organisms include slow growth rates, high viscosity, mixing problems due to the formation of large mycelial clumps and complex downstream processing [16]. Enhanced expression of the SsgA protein in S. lividans reduces such problems significantly as it favours fragmented growth due to enhanced cell division [15]. Interestingly, SsgA is also linked to the expression of all of the components of the secretion machinery. For example, enhanced expression of SsgA results in a strong increase in the secretion of tyrosinase (which is a substrate for the Tat system) in much shorter fermentation time, and expression of genes encoding components of the Tat and Sec secretion machinery is strongly upregulated in $s s g A$ null mutants [14]. The latter is most likely the result of a feedback response to compensate for the absence of the important morphoprotein SsgA [14]. As a result of the improved growth and secretion capacity, the enhanced expression of SsgA has been shown to be potentially very advantageous for protein production [16]. Indeed, xylanase and amylase production increased by 40 and $70 \%$, respectively, in S. lividans GSAL1, which overexpresses SsgA when compared to the wild type strain (Fig. 4b, d).

\section{Conclusions}

The use of Streptomyces as a platform for high-level proteins production requires proper optimization for each protein of interest. We constructed a set of bifunctional plasmids (E. coli-Streptomyces) with strong and inducible promoters that are convenient for protein 
production in Streptomyces. Combination with hosts with either enhanced expression of SsgA or lacking specific transcriptional repressors further improved enzyme production.

\section{Methods}

Strains and culture conditions

Escherichia coli DH5 $\alpha$ [37] was used for the cloning and isolation of plasmids. It was grown in Luria-Bertani liquid broth or on LB agar. DNA manipulations in E. coli were done following standard procedures [38].

Streptomyces lividans 1326 and its derivative strains, GSAL1 [16], $\Delta x \ln R$, and $\Delta b x l R$ were used as hosts. The genome sequence of S. lividans 1326 has been published [39] and is available at StrepDB (http://strepdb.streptomyces.org.uk). GSAL1 is a transformant of S. lividans harbouring the integrative plasmid pGWS4-SD, which results in the effective overproduction of the SsgA protein [15]. The $\Delta x \ln R$ and $\Delta b x l R$ mutants were prepared and isolated according to protocols described previously [40]. In the $\Delta x \ln R$ mutant, nucleotides -146 to +756 relative to the start codon of SLI4452 were replaced by a $62 \mathrm{nt}$ scar of the loxP recombination site including two Xbal sites. In the $\Delta b x l R$ mutant, nts +1 to +1127 relative to the start of SLI7232 were replaced. Strains were grown on R2YE agar plates for transformation, on MSA agar plates for sporulation [41] and in YE $(1 \%(w / v)$ Yeast extract, $\left.5 \mathrm{mM} \mathrm{MgCl}_{2} \mathrm{pH} 7.2\right)$ or YES (1\% (w/v) Yeast extract, $10.3 \%(\mathrm{w} / \mathrm{v})$ sucrose, $\left.5 \mathrm{mM} \mathrm{MgCl}_{2} \mathrm{pH} 7.2\right)$ liquid media supplemented with $1 \%(\mathrm{w} / \mathrm{v})$ of xylose or $5 \%$ $(\mathrm{w} / \mathrm{v})$ of fructose for protein expression [20]. Neomycin, $15 \mu \mathrm{g} / \mathrm{mL}$, or thiostrepton, $2.5 \mu \mathrm{g} / \mathrm{mL}$, were added to the culture depending of the plasmid used. Liquid-grown cultures were carried out in baffled flasks at $28{ }^{\circ} \mathrm{C}$ and $200 \mathrm{rpm}$. DNA manipulations in Streptomyces were carried out essentially as described by Kieser et al. [41].

\section{Plasmid constructions}

All plasmids used in the present work are listed in Table 1. PCR amplification of each promoter was accomplished with oligonucleotides including EcoRI and NdeI restriction sites (Table 2). PCR products were purified by agarose gel electrophoresis, digested with EcoRI and NdeI, and cloned in plasmid pNX30 [5] digested with the same restriction enzymes.

pNXA1 and pNXA2 were constructed by PCR amplification of the signal peptide of the $\alpha$-amylase (EMBL X57568) from S. griseus IMRU 3570 with oligonucleotides including NdeI and MreI restriction sites (MreI cuts just after the sequence that encodes the signal peptide of the xylanase and the correct frame was conserved in the construction) (Table 2). PCR products were purified by agarose gel electrophoresis, digested with NdeI and MreI and cloned in plasmid pNX24 [22] digested with the same restriction enzymes. The new constructs have the $\alpha$-amylase signal peptide fused in-frame with the xys $A$ gene.

The plasmids pNXAmy and pNUFAmy were constructed by replacing xylanase gene by the $\alpha$-amylase ORF in pNX24 and pNUF5 respectively. The $\alpha$-amylase gene (X57568.1) was amplified from S. griseus genome with oligonucleotides MRG11 and MRG12 (Table 2).

The inserts of all plasmid constructions were sequenced on both strands using a Perkin-Elmer ABI Prism 377 DNA sequencer. In silico plasmids were done with the Gene Construction Kit (GCK, Textco).

\section{Protein analysis}

Protein profiles were analysed by denaturing polyacrylamide gel electrophoresis (SDS-PAGE) in a MiniProtean II system (Bio-Rad). Proteins were detected by $0.5 \%$ Coomassie brilliant blue R staining and Low-Range SDSPAGE Standards (Bio-Rad) were used as markers. Xylanase and amylase band intensities were analysed with ImageJ software [44].

\section{Xylanase and amylase activities assays}

Xylanase and amylase activities were measured by the dinitrosalicylic acid (DNS) method, using xylose or maltose as standards respectively [42]. One unit of xylanase or amylase activities was defined as the amount of enzyme required releasing $1 \mu \mathrm{mol}$ of reducing sugars, (expressed as xylose equivalents or maltose equivalents), in $1 \mathrm{~min}$. All data shown are means of at least three different experiments.

\section{SLAC in-gel assay}

Secreted SLAC activity was determined in the supernatant of liquid cultures of the wild type S. lividans 1326, $\triangle x \ln R$ and $\triangle b x l R$ strains harbouring the SLAC reporter plasmid pEPOS101. Cells were grown in YES medium supplemented with $1 \%$ xylose, $20 \mu \mathrm{M} \mathrm{Cu}(\mathrm{II})$ and $2.5 \mu \mathrm{g} /$ $\mathrm{mL}$ thiostrepton and samples $(1.5 \mathrm{~mL})$ were taken after $24,48,72$ and $96 \mathrm{~h}$ of incubation at $28{ }^{\circ} \mathrm{C}$. In-gel SLAC activity stain was done essentially according to Endo et al. [43]. Samples were mixed 1:1 with SDS-PAGE loading buffer without $\beta$-mercaptoethanol and without boiling and loaded directly on the gels. Following electrophoresis and detection of SLAC with N,N-Dimethyl-p-phenylenediamine sulfate salt (DMPPDA, Sigma D-4790) and naphthol, digital images of the gels were taken and analysed with ImageJ [44]. Band intensities were normalized 
Table 2 Oligonucleotides used in this work

\begin{tabular}{|c|c|c|}
\hline Name & Sequence $5^{\prime}-3^{\prime}$ & Use \\
\hline LS-001 & TTTTTTGAATTCTGTGCGGCTGCCCTTCCGCC & $\begin{array}{l}\text { Forward oligonucleotide for cloning the glpQp. The sequence recognized by EcoRl is in } \\
\text { italics }\end{array}$ \\
\hline LS-002 & TTTTTTCATATGCGTACTCCTCGCGTCGAACG & $\begin{array}{l}\text { Reverse oligonucleotide for cloning the glpQp. The sequence recognized by Ndel is in } \\
\text { italics }\end{array}$ \\
\hline LS-Amy & TTTTTTCATATGGCCCGCAGACTCGCCACC & $\begin{array}{l}\text { Forward oligonucleotide to introduce the amylase signal peptide. The sequence recog- } \\
\text { nized by Ndel is in italics }\end{array}$ \\
\hline LS-003 & TTTTTTCGCCGGCGGCAGCGGCGGGTGTG & $\begin{array}{l}\text { Reverse oligonucleotide to introduce the amylase signal peptide. The sequence recog- } \\
\text { nized by Mrel is in italics }\end{array}$ \\
\hline LS-004 & TTTTTTCGCCGGCGGGCGGGGCGGCAGCGGC & $\begin{array}{l}\text { Reverse oligonucleotide to introduce the amylase signal peptide with three additional } \\
\text { amino acids. The sequence recognized by Mrel is in italics }\end{array}$ \\
\hline LS-023 & TTTTTTGAATTCGGTACCAGCCCGACCCGAGC & $\begin{array}{l}\text { Forward oligonucleotide for cloning the ermE* } p \text {. The sequence recognized by EcoRI is in } \\
\text { italics }\end{array}$ \\
\hline LS-024 & TTTTTTCATATGACCAACCGGCACGATTGTGCC & $\begin{array}{l}\text { Reverse oligonucleotide for cloning the ermE* } p \text {. The sequence recognized by Ndel is in } \\
\text { italics }\end{array}$ \\
\hline LS-026 & TTTTTTGAATTCGGGGATGACCACCGCGGGAG & Forward oligonucleotide for cloning the vsip. The sequence recognized by EcoRI is in italics \\
\hline LS-027 & TTTTTTGATATCGGTGAACTCTCCTTCGATCGATG & Reverse oligonucleotide for cloning the vsip. The sequence recognized by EcoRV is in italics \\
\hline RS-003 & TTTTTTGAATTCGGGCTTCTCCCTCTTCCGCGGG & Forward oligonucleotide for cloning the $x y / p$. The sequence recognized by EcoRI is in italics \\
\hline RS-004 & TTTTTTCATATGCCGCGGCTCCTCACTCGCTGC & Reverse oligonucleotide for cloning the xylp. The sequence recognized by Ndel is in italics \\
\hline LS-celF & TTTTTTGAATTCGGCCGGCCGCTCCCGTCTGGC & $\begin{array}{l}\text { Forward oligonucleotide for cloning the celAp. The sequence recognized by EcoRl is in } \\
\text { italics }\end{array}$ \\
\hline LS-celR & TTTTTTCATATGCAGTACCTCGATTTCAGAGGA & Reverse oligonucleotide for cloning the celAp. The sequence recognized by Ndel is in italics \\
\hline MRG11 & TTTTTTCATATGGCCCGCAGACTCCGCACC & $\begin{array}{l}\text { Forward oligonucleotide for cloning amylase ORF. The sequence recognized by Ndel is in } \\
\text { italics }\end{array}$ \\
\hline MRG12 & TTTTTTCTCGAGGCCGCGCCAGGTGTCGTTGAG & $\begin{array}{l}\text { Reverse oligonucleotide for cloning amylase ORF. The sequence recognized by Xhol is in } \\
\text { italics }\end{array}$ \\
\hline $4215 U \mathrm{pF}$ & GCGGAATTCAGCTGCTCAAGGACGCCGGC & $\begin{array}{l}\text { Forward oligonucleotide for the cloning upstream flank of XInR. The sequence recognized } \\
\text { by EcoRI is in italics }\end{array}$ \\
\hline $4215 U p R$ & GCGGGATCCCATCCCGTGGGCCTCCTCTCC & $\begin{array}{l}\text { Reverse oligonucleotide for the cloning upstream flank of XInR. The sequence recognized } \\
\text { by BamHI is in italics }\end{array}$ \\
\hline 4215DwF & GCGTCTAGAGTAACTCGAGCGGTCTCGCCC & $\begin{array}{l}\text { Forward oligonucleotide for the cloning downstream flank of XInR. The sequence recog- } \\
\text { nized by Xbal is in italics }\end{array}$ \\
\hline 4215DwR & CGCAAGCTTCCGCATCTGCTGGAGCCGG & $\begin{array}{l}\text { Reverse oligonucleotide for the cloning downstream flank of XInR. The sequence recog- } \\
\text { nized by HindIII is in italics }\end{array}$ \\
\hline $7232 \mathrm{UpF}$ & GCGGAATTCGTGAGGTGTGTGGTCATGAGCC & $\begin{array}{l}\text { Forward oligonucleotide for the cloning of upstream flank of BxIR. The sequence recog- } \\
\text { nized by EcoRl is in italics }\end{array}$ \\
\hline $7232 U p R$ & CGCTCTAGACCGGGCGCCCACCTCAAC & $\begin{array}{l}\text { Reverse oligonucleotide for the cloning upstream flank of BxIR. The sequence recognized } \\
\text { by Xbal is in italics }\end{array}$ \\
\hline 7232DwF & GCGTCTAGAGGCTCCTACCGGCCGGGC & $\begin{array}{l}\text { Forward oligonucleotide for the cloning downstream flank of BxIR. The sequence recog- } \\
\text { nized by Xbal is in italics }\end{array}$ \\
\hline 7232DwR & CGCAAGCTTGTGCCGCGGCCGGAGCCG & $\begin{array}{l}\text { Reverse oligonucleotide for the cloning downstream flank of BxIR. The sequence recog- } \\
\text { nized by HindlII is in italics }\end{array}$ \\
\hline
\end{tabular}

for the biomass (dry weight) and expressed in arbitrary units per dry weight.

\section{Additional file}

Additional file 1. Supplementary tables (S1-S6) containing enzyme quantification by activity or by ImageJ.

\section{Authors' contributions}

LS performed most of the experimental work; GPVW and EV carried out the studies on the SsgA overproducer strain and the repressor mutant strains; MD and RS selected the different promoters to be studied, directed the work and wrote the manuscript with contributions from all authors. All authors read and approved the final manuscript.

\section{Author details}

${ }^{1}$ Instituto de Biología Funcional y Genómica/Departamento de Microbiología y Genética, Consejo Superior de Investigaciones Científicas (CSIC)/Universidad de Salamanca, C/Zacarías González n², 37007 Salamanca, Spain. ${ }^{2}$ Molecular Biotechnology, IBL, Sylvius Laboratory, Leiden University, Leiden, The Netherlands.

\section{Acknowledgements}

This work has been supported by ERA-IB grants EUI2008-03631 and PCIN2014-067 of the Ministerio de Economía y Competitividad, to RS. EV and GPvW acknowledge the Nederlandse Organisatie voor Wetenschappelijk Onderzoek (NWO)/Advanced Chemical Technologies for Sustainability (ACTS) for grant 
053.80.703 in the ERA-IB framework (EIB.08.013 EPOS). The authors also thank the CSIC for the co-financing of this publication in Open Access through its Unit of Information Resources for Research (URICI). Thanks are due to Dr. JA Gil for the S. griseus DNA, to Dr. J. Anne for his suggestions on signal peptide constructions, to MJ Jiménez Rufo for her excellent technical work and to N. Skinner for supervising the English version of the manuscript.

\section{Competing interests}

The authors declare that they have no competing interests.

Received: 26 October 2015 Accepted: 19 January 2016 Published online: 04 February 2016

\section{References}

1. de Marco A. Recombinant polypeptide production in E. coli: towards a rational approach to improve the yields of functional proteins. Microb Cell Fact. 2013;12:101

2. Hochkoeppler A. Expanding the landscape of recombinant protein production in Escherichia coli. Biotechnol Lett. 2013;35:1971-81.

3. Vrancken K, Anne J. Secretory production of recombinant proteins by Streptomyces. Future Microbiol. 2009;4:181-8.

4. Díaz M, Adham SA, Ramón D, Gil JA, Santamaría RI. Streptomyces lividans and Brevibacterium lactofermentum as heterologous hosts for the production of $X_{22}$ xylanase from Aspergillus nidulans. Appl Microbiol Biotechnol. 2004;65:401-6.

5. Díaz M, Ferreras E, Moreno R, Yepes A, Berenguer J, Santamaría R. Highlevel overproduction of Thermus enzymes in Streptomyces lividans. Appl Microbiol Biotechnol. 2008;79:1001-8.

6. Zhu Y, Wang L, Du Y, Wang S, Yu T, Hong B. Heterologous expression of human interleukin-6 in Streptomyces lividans TK24 using novel secretory expression vectors. Biotechnol Lett. 2011;33:253-61.

7. Ayadi DZ, Chouayekh H, Mhiri S, Zerria K, Fathallah DM, Bejar S. Expression by Streptomyces lividans of the rat alpha integrin CD11b A-domain as a secreted and soluble recombinant protein. J Biomed Biotechnol. 2007:2007:54327.

8. Kim MR, Choeng YH, Chi WJ, Kang DK, Hong SK. Heterologous production of streptokinase as a secretory form in Streptomyces lividans and nonsecretory form in Escherichia coli. J Microbiol Biotechnol. 2010;20:132-7.

9. Noda S, Ito Y, Shimizu N, Tanaka T, Ogino C, Kondo A. Over-production of various secretory-form proteins in Streptomyces lividans. Protein Expr Purif. 2010;73:198-202

10. Anné J, Vrancken K, Van Mellaert L, Van Impe J, Bernaerts K. Protein secretion biotechnology in Gram-positive bacteria with special emphasis on Streptomyces lividans. Biochim Biophys Acta. 2014;1843:1750-61.

11. Nielsen J. Modelling the morphology of filamentous microorganisms. Trends Biotechnol. 1996;14:438-43.

12. van Wezel GP, McKenzie NL, Nodwell JR. Chapter 5. Applying the genetics of secondary metabolism in model actinomycetes to the discovery of new antibiotics. Methods Enzymol. 2009;458:117-41.

13. van Dissel $D$, Claessen $D$, Roth $M$, van Wezel GP. A novel locus for mycelial aggregation forms a gateway to improved Streptomyces cell factories. Microb Cell Fact. 2015;14:44.

14. Noens EE, Mersinias V, Willemse J, Traag BA, Laing E, Chater KF, Smith CP, Koerten HK, van Wezel GP. Loss of the controlled localization of growth stage-specific cell-wall synthesis pleiotropically affects developmental gene expression in an ssgA mutant of Streptomyces coelicolor. Mol Microbiol. 2007;64:1244-59.

15. van Wezel GP, van der Meulen J, Kawamoto S, Luiten RG, Koerten HK, Kraal B. ssgA is essential for sporulation of Streptomyces coelicolor A3(2) and affects hyphal development by stimulating septum formation. J Bacteriol. 2000;182:5653-62

16. van Wezel GP, Krabben P, Traag BA, Keijser BJ, Kerste R, Vijgenboom E, Heijnen JJ, Kraal B. Unlocking Streptomyces spp. for use as sustainable industrial production platforms by morphological engineering. Appl Environ Microbiol. 2006;72:5283-8.

17. Van Mellaert L, Lammertyn E, Schacht S, Proost P, Van Damme J, Wroblowski B, Anne J, Scarcez T, Sablon E, Raeymaeckers J, Van
Broekhoven A. Molecular characterization of a novel subtilisin inhibitor protein produced by Streptomyces venezuelae CBS762.70. DNA Seq. 1998;9:19-30.

18. Bibb MJ, Janssen GR, Ward JM. Cloning and analysis of the promoter region of the erythromycin resistance gene (ermE) of Streptomyces erythraeus. Gene. 1985;38:215-26.

19. Ruiz-Arribas A, Sánchez P, Calvete JJ, Raida M, Fernández-Abalos JM, Santamaría RI. Analysis of xysA, a gene from Streptomyces halstedii JM8 that encodes a 45-kilodalton modular xylanase, Xys1. Appl Environ Microbiol. 1997;63:2983-8.

20. Díaz M, Esteban A, Fernández-Ábalos JM, Santamaría RI. The high-affinity phosphate-binding protein PstS is accumulated under high fructose concentrations and mutation of the corresponding gene affects differentiation in Streptomyces lividans. Microbiology. 2005;151:2583-92.

21. Fernández-Abalos JM, Reviejo V, Díaz M, Rodríguez S, Leal F, Santamaría RI. Posttranslational processing of the xylanase Xys $1 \mathrm{~L}$ from Streptomyces halstedii JM8 is carried out by secreted serine proteases. Microbiology. 2003;149:1623-32.

22. Adham SA, Honrubia P, Díaz M, Fernández-Ábalos JM, Santamaría RI, Gil JA. Expression of the genes coding for the xylanase Xys1 and the cellulase Cel1 from the straw-decomposing Streptomyces halstedii JM8 cloned into the amino-acid producer Brevibacterium lactofermentum ATCC13869. Arch Microbiol. 2001;177:91-7.

23. Lammertyn E, Desmyter S, Schacht S, Van Mellaert L, Anne J. Influence of charge variation in the Streptomyces venezuelae alpha-amylase signal peptide on heterologous protein production by Streptomyces lividans. Appl Microbiol Biotechnol. 1998;49:424-30.

24. Guan C, Cui W, He X, Hu X, Xu J, Du G, Chen J, Zhou Z. Construction and development of a novel expression system of Streptomyces. Protein Expr Purif. 2015;113:17-22.

25. Vigal T, Gil JA, Daza A, García-González MD, Villadas P, Martín JF. Effects of replacementof promoters and modification of the leader peptide region of the amy gene of Streptomyces griseus on synthesis and secretion of a-amylase by Streptomyces lividans. Mol Gen Genet. 1991;231:88-96.

26. Jakimowicz D, van Wezel GP. Cell division and DNA segregation in Streptomyces: how to build a septum in the middle of nowhere? Mol Microbiol. 2012;85:393-404.

27. Willemse J, Borst JW, de Waal E, Bisseling T, van Wezel GP. Positive control of cell division: FtsZ is recruited by SsgB during sporulation of Streptomyces. Genes Dev. 2011;25:89-99.

28. Rodríguez S, Santamaría RI, Fernández-Ábalos JM, Díaz M. Identification of the sequences involved in the glucose-repressed transcription of the Streptomyces halstedii JM8 xysA promoter. Gene. 2005;351:1-9.

29. Tsujibo H, Kosaka M, Ikenishi S, Sato T, Miyamoto K, Inamori Y. Molecular characterization of a high-affinity xylobiose transporter of Streptomyces thermoviolaceus OPC-520 and its transcriptional regulation. J Bacteriol. 2004;186:1029-37.

30. Rigali S, Derouaux A, Giannotta F, Dusart J. Subdivision of the helix-turnhelix GntR family of bacterial regulators in the FadR, HutC, MocR, and YtrA subfamilies. J Biol Chem. 2002;277:12507-15.

31. Machczynski MC, Vijgenboom E, Samyn B, Canters GW. Characterization of SLAC: a small laccase from Streptomyces coelicolor with unprecedented activity. Protein Sci. 2004;13:2388-97.

32. Nakashima N, Mitani Y, Tamura T. Actinomycetes as host cells for production of recombinant proteins. Microb Cell Fact. 2005;4:7.

33. Binnie C, Cossar JD, Stewart DI. Heterologous biopharmaceutical protein expression in Streptomyces. Trends Biotechnol. 1997;15:315-20.

34. Nijland R, Kuipers OP. Optimization of protein secretion by Bacillus subtilis. Recent Pat Biotechnol. 2008;2:79-87.

35. Esteban A, Díaz M, Yepes A, Santamaría Rl. Expression of the pstS gene of Streptomyces lividans is regulated by the carbon source and is partially independent of the PhoP regulator. BMC Microbiol. 2008;8:201.

36. Sola-Landa A, Moura RS, Martín JF. The two-component PhoR-PhoP system controls both primary metabolism and secondary metabolite biosynthesis in Streptomyces lividans. Proc Natl Acad Sci U S A. 2003;100:6133-8

37. Hanahan D. Studies on transformation of Escherichia coli with plasmids. J Mol Biol. 1983;166:557-80.

38. Sambrook J, Fritsch E, Maniatis T. Molecular cloning: a laboratory manual. 2nd ed. Cold Spring Harbor: Cold Spring Harbor Laboratory; 1989. 
39. Cruz-Morales P, Vijgenboom E, Iruegas-Bocardo F, Girard G, Yanez-Guerra LA, Ramos-Aboites HE, Pernodet JL, Anne J, van Wezel GP, Barona-Gomez F. The genome sequence of Streptomyces lividans 66 reveals a novel tRNAdependent peptide biosynthetic system within a metal-related genomic island. Genome Biol Evol. 2013;5:1165-75.

40. Blundell KL, Wilson MT, Svistunenko DA, Vijgenboom E, Worrall JA. Morphological development and cytochrome c oxidase activity in Streptomyces lividans are dependent on the action of a copper bound Sco protein. Open biology. 2013;3:120163.

41. Kieser T, Hopwood DA, Bibb JM, Chater KF, Buttner MJ. Practical Streptomyces genetics. Norwich: John Innes Foundation; 2000.

42. Biely P, Mislovicova D, Toman R. Soluble chromogenic substrates for the assay of endo-1,4-ß-xylanases and endo-1,4-ß-glucanases. Anal Biochem. $1985 ; 144: 142-6$
43. Endo K, Hosono K, Beppu T, Ueda K. A novel extracytoplasmic phenol oxidase of Streptomyces: its possible involvement in the onset of morphogenesis. Microbiology. 2002;148:1767-76.

44. Schneider CA, Rasband WS, Eliceiri KW. NIH Image to ImageJ: 25 years of image analysis. Nat Methods. 2012;9:671-5.

45. García-González MD, Martín JF, Vigal T, Liras P. Characterization, expression in Streptomyces lividans, and processing of the amylase of Streptomyces griseus IMRU 3570: two different amylases are derived from the same gene by an intracellular processing mechanism. J Bacteriol. 1991;173:2451-8.

\section{Submit your next manuscript to BioMed Central and we will help you at every step:}

- We accept pre-submission inquiries

- Our selector tool helps you to find the most relevant journal

- We provide round the clock customer support

- Convenient online submission

- Thorough peer review

- Inclusion in PubMed and all major indexing services

- Maximum visibility for your research

Submit your manuscript at www.biomedcentral.com/submit

() Biomed Central 